\title{
Assessment of Quo and Desirable Status of Adult Education Curricula in Elementary and Post-elementary Education
}

\author{
Leila Rezaii $^{1, ~}$, Alireza Assareh ${ }^{1}$, Rezvan Hakimzade ${ }^{2}$, Bahram Saleh Sedghpour $^{1}$ \\ ${ }^{1}$ Humanstic Science Department, Shahid Rajaii Teacher Training Center, Tehran, Iran \\ ${ }^{2}$ Educational Department, Tehran University, Tehran, Iran \\ Email address: \\ rezaii.leli@gmail.com (L. Rezaii), alireza_assareh@yahoo.com (A. Assareh), hakimzadeh@ut.ac.ir (R. Hakimzade), \\ Bahramsaleh@gmail.com (B. S. Sedghpour) \\ ${ }^{*}$ Corresponding author
}

\section{To cite this article:}

Leila Rezaii, Alireza Assareh, Rezvan Hakimzade, Bahram Saleh Sedghpour. Assessment of Quo and Desirable Status of Adult Education Curricula in Elementary and Post-elementary Education. International Journal of Elementary Education. Vol. 9, No. 4, 2020 , pp. 88-99. doi: $10.11648 /$ j.jjeedu.20200904.12

Received: March 15, 2020; Accepted: March 30, 2020; Published: December 16, 2020

\begin{abstract}
The overall purpose of this study is to investigate the current and desirable status of adult education curricula in elementary and post-elementary education. In this study, exploratory mixed method was used. In the quantitative section the statistical population was all professors and experts in the field of adult education in the country that 25 people were selected based on theoretical and snowball sampling method. Samples in the qualitative section included all upstream documents related to adult education curriculum and professors, curriculum experts, and adult education that ten people were selected through theoretical sampling (Theoretical) and snowball. The research tool in the qualitative section was semi-structured interview and in the quantitative section a researcher-made questionnaire (based on the qualitative section results). Quantitative data analysis was performed using descriptive and inferential statistics and qualitative data analysis using thematic analysis. The quantitative and qualitative results of the present study showed that twelve components of philosophical foundations, sociological foundations, psychological foundations, political foundations, content, goals, evaluation, teaching and learning strategies, learning time and space, teaching and learning activities, learning materials and teamworking form the cornerstone of the post-elementary curriculum. The results of this study showed that there is a significant difference between the current situation and the desirable status of adult education curricula in elementary and post-primary education.
\end{abstract}

Keywords: Adult Education, Curriculum, Primary Education, Post-elementary Education

\section{Introduction}

Adult education system, as the most prominent manifestation of human resources investment, plays an important role in the training and provision of efficient human capital. This system with a significant share of each country's budget can have a decisive role in different economic, cultural and political aspects of society. Today, the role of literacy, knowledge and awareness in the technological, economic and social development of societies is well known. That is why the development of education and the reduction of illiteracy is one of the important indicators of progress. If our primary focus is on human development, growth and excellence, the first step is to equip them with the skills that can best communicate with each other and prepare them for a constructive and effective role in society. Therefore, education and its infrastructure, literacy is one of the most important tasks. Adult literacy and education as a factor in building these capacities for productive and effective strata of sustainable development is of particular importance.

Adult education is a broad concept that encompasses all formal, informal and casual adult learning activities in a variety of occupational, social, political, economic, 
cultural, educational, religious, industrial, agricultural and educational contexts. As Ryan [1] put it: " The realm of adult education is as the breadth as the life".". Adult education is an activity organized to create a learning community through the transfer of up-to-date knowledge and skills to adults so that they can move towards evolution and excellence and participate actively in the social, cultural, political and economic life of their community [2]. One of the goals of education is to promote the level of general culture of society which requires the improvement of knowledge and general literacy of the community. In this way, literacy has been considered as a central axis of general culture development [3].

Given that the literacy movement plans include elementary education by the end of elementary school, as well as the specific characteristics of adults, as well as the number of people who graduate annually and who have a high school diploma and are interested in studying in the post-elementary period, this study seeks to investigate the factors affecting the adult education curriculum by describing the quo status, drawing the desirable status of adult education in the elementary and post-elementary education.

Unfortunately, the evidence suggests that many children are enrolled in school each year, but there is growing evidence that a large number of them are connected to the employment and work flow after acquiring primary literacy skills. It means that after a while, these children are joining the low-educated adults, and even thousands of students drop out of school every year, with an uncertain future ahead. To this end, the most important goals and needs of the education system can be to ensure people's selfawareness and effective participation in working life (Lindsay \& Johnson, 1990), improvement and attention to the major issues and social developments of the present day and the ability to play an active role in social development, increasing awareness of the relationships between people and their physical and cultural environments and enhancing their desire for environmental remediation and the preservation of nature, public heritage and public property [4], the use of mass media, especially radio, television, cinema, the press and the interpretation of various messages that it is presented by the community [5], the training of active and knowledgeable workforce whose work reduces the development gap between regions and countries [6]. In short, can name talent boom, rich Adaptation of knowledge, information and life skills of adults in order to transform their attitudes and behavior in both personal and social aspects [7]. In Iran, literacy has been the subject of various programs in the country for many years, and it is the priority of governments of the time despite shortcomings in this area, including inadequate textbooks in introductory Literacy courses ([8-10]; Chopani Keshtaii and Bakhshayeshi, 1998; Hafezi, 2000); inapplicability and Inadequacy of Education with Cultural Characteristics ([11-13] and Problems Related to management of plans
[14], policy making false and multiple bugs in the implementation of programs in this area has not been made significant progress [15].

In recent years, especially since 2011, a wide range of structural and content reforms have begun. Integration of executive management across the country with the integration of the Literacy and Education Movement Organization, restructuring of literacy courses that reached the end of elementary education in the new structure of literacy development (sixth grade), re-authoring of all textbooks in literacy courses, development of root program Kennedy illiteracy, revitalization of the Supreme Council for the Support of Literacy, formation of citizenship literacy level and establishment of a registry database, concluding about 30 agreements with government and non-governmental organizations, designing multiple projects (such as training illiterate family members)., Age group 10-20, education and skills integration plan Computer training foreign nationals, tribal education, training illiterate parents, students, etc.), including measures that to show the growth of literacy rates in the country and to keep pace with changes in the country and the world.

Based on the results, teacher-centered and learnercentered learning activities in all books were based on expected with content and text learning index of all three books and the way they were edited was inactive. The book's shapes and images learning index, familiarity with the life of plants, animals, and so forth were based on expected, and their formulation active, and the book's shapes and images learning index was less than expected for facts about life and its editing method was inactive. Mir Hosseini [16] also conducted a study entitled "Content Analysis of Non-literate Books of Literacy Movement Learners, which showed that in literacy books, life skills needs (to say" no", interpersonal trust, self-esteem, social connection and anger control), Spiritual education, proper occupational education, sport education, continuing education, healthy nutrition education, and health education have not been addressed and awareness of sexuality has not been addressed. Therefore, in compiling literacy textbooks the needs of this group of learners should be addressed Horner (2008) examines the impact of teaching methods on the andragogy approach in the context of the academic environment, and the researcher states that the andragogy approach in the context of higher education context isn't ideal and he designed quasi-experimental research with andragogy approach in the context of the university's foundation [17].

Perrin [18] has examined the content validity of andragogy and whether it actually reflects the learning characteristics of adults. Learners return to education to earn their future money and jobs, and are interested in anagogical strategies in the classroom such as selfleadership, skill building, and choice of training, tailored to their needs.

Also there are great deal of emphasizes in high-level 
documents on the importance of the higher education system and its role in the cultural promotion of the country including according to Article 30 of the Constitution of the Islamic Republic of Iran: "the government is obliged to provide free education to all people by the end of high school and expand the means of higher education to the extent of selfsufficiency for free."

Also, according to the twenty-year vision document which is one of the most important documents after the constitution, the characteristics of the Iranian society have been seen in the horizon of this landscape in 1404, that is emphasized on the development of culture, education and research.

According to this perspective, in the Fourth Development Plan, in the area of eradication of illiteracy, was designed to achieve literacy of persons under at least thirty years until the end of the Fourth Development Plan, and subsequently in the Fifth Development Plan, Completion of the Fifth Five Year Development Plan will achieve full literacy of the 10-49 year-old group

Dispersal in the adult education curriculum, lack of a coherent and integrated system for identifying, accepting and recruiting illiterate adults, inadequate text and curriculum content, inadequate educational facilities and facilities, inappropriate curriculum and taste ractivities and process of education, outputs and in addition to the above problems, the lack of accurate statistics and information from illiterate adults has made literacy difficult to control.

Another important issue in this area is the illiterate and illiterate reluctance to complete and complete literacy courses. The main problem of the target community itself is the illiterate person, who are not required to attend literacy programs and do not consider themselves obliged to become literate during the government effort and investments made for literacy. Another important issue in this area is the illiterate and illiterate reluctance to complete and complete literacy courses. The main problem of the target community itself is the illiterate, who are not required to attend literacy programs and do not consider themselves obliged to become literate during the government effort and investments made for literacy.

Studies show that despite efforts, illiterate entry is not blocked, about $3 \%$ of 6 -year-olds do not enter elementary school annually, plus the transition rate from elementary to upper secondary is up to $100 \%$, so There are about 164,000 survivors primary school, about 225,000 in the first secondary and about 592,000 in the second.

The severity of falls in girl's at all three levels of education was higher than boys. Students in rural areas and girls in secondary school are more deprived. The rate of transition from secondary school to secondary school, as well as the percentage of girls out of all secondary school students and the gross enrollment rate, all indicate that girls and rural populations have always been in a poorer position.

The statistics reflect the fact that a significant portion of the country's active and effective population are lacks the knowledge and skills needed to play a role in the country's development and development process within the context of the Islamic-Iranian model of achieving and achieving the goals of the 20 -year vision of the country.

The results of comparative studies of the adult education system in other countries show that in most countries the purpose of the adult education system is to prepare people to enter the labor market in order to achieve economic and social goals, to educate good citizens with the capacity to respond to the needs of today, Bridging educational gaps and establishing greater equality and social justice in the field of education is the development of adult personality and the development of membership and participation in society. Adult education should be based on experimentation and the project, the learners' needs and interests. Adult education should consider the use of communication and technological information in adult education with emphasis on technical and vocational training and flexibility in time and place. The problem that has arisen for the researcher in this research, given that the researcher has been active in this field for many years and is concerned with addressing and resolving it, how is that the current and desirable status of adult education in primary and secondary education in post-elementary?

The researcher in this research seeks to answer the following questions

1. What is the quo status of adult education curriculum in the country in primary and post-elementary education?

2. What can be the desirable status of adult education curriculum in the country in the post-elementary?

\section{Research Methodology}

The purpose of the present study is descriptive and is practical in terms of purpose. Due to the nature of the problem and the objectives of the study, a mixed method (quantitative and qualitative) and exploratory was used. In order to collect data in the qualitative part of this research, which is the dominant part, documentary research methods were used and then the qualitative part results were used to develop a researcher-made questionnaire to answer the quantitative research question; Data were collected using a researcher-made questionnaire.

The statistical population of this study included: All upstream documents related to adult education and training curriculum such as the Constitution of the country, Basic Education Transformation Document, National Curriculum Document, Comprehensive Scientific Plan of the Country, Vision Document in Horizon 1404, Policies the whole system has been approved by the Supreme Council of the Cultural Revolution and the Supreme Council of Education, the Statute of the Literacy Movement and the Eradication Program [19].

For analyzing research data, upstream documents, scientific papers, research articles, books, Iranian Internet resources and curriculum reviews of some countries in the 
field of adult education and related elementary and postelementary curricula were reviewed. Descriptive statistics (frequency, mean, etc.) and inferential statistics (factor analysis, independent t-test) were used.

\section{Result}

Question 1: How is the quo status of adult education curriculum in the country in primary and post-elementary education?

Table 1. Descriptive indicators of research variables (quo status).

\begin{tabular}{|c|c|c|c|c|c|c|c|c|c|}
\hline Variables & Number & Average & Middle & extent & $\begin{array}{l}\text { Standard } \\
\text { deviation }\end{array}$ & Variance & $\begin{array}{l}\text { variation } \\
\text { range }\end{array}$ & Minimum & $\operatorname{Max}$ \\
\hline philosophical foundations & 25 & 2396. & 2500. & 2500 & 0618. & 0515. & 3650. & 1250. & 5000. \\
\hline sociological foundations & 25 & 2499. & 2600. & 3000. & 0696. & 0486. & 3800. & 1200. & 5000. \\
\hline psychological foundations & 25 & 3421. & 2500. & 2500. & 0696. & 0484. & 4000. & 1000. & 5000. \\
\hline political foundations & 25 & 2426. & 2333. & 3000. & 0848. & 0619. & 4000. & 1000. & 5000. \\
\hline content & 25 & 2318. & 2333. & 2333. & 0666. & 0603. & 4000. & 1000. & 5000. \\
\hline goals & 25 & 2410. & 2333. & 3000. & 0860. & 0639. & 4000. & 1000. & 5000. \\
\hline evaluation & 25 & 3461. & 2666. & 3000. & 0846. & 0616. & 4000. & 1000. & 5000. \\
\hline teaching and learning strategies & 25 & 2464. & 2666. & 3000. & 0804. & 0646. & 4000. & 1000. & 5000. \\
\hline learning time and space & 25 & 3440. & 2333. & 3000. & 0830. & 0689. & 4000. & 1000. & 5000. \\
\hline teaching and learning activities & 25 & 2586. & 3000. & 3000. & 0826. & 0683. & 4000. & 1000. & 5000. \\
\hline learning materials and resources & 25 & 3566. & 3000. & 3000. & 0801. & 0641. & 3333. & 1666. & 5000. \\
\hline
\end{tabular}

Table 1 lists the 12 descriptive indicators of the research. As can be seen, the variables of psychological foundations (mean 3.42), evaluation (mean 3.46), learning time and space (mean 3.46) are also learning materials and resources (With a mean of 3.56, they are above the theoretical mean of the research instrument (mean 3). It can be said that among the
12 variables studied, these variables have the closest distance to desirable status. In other variables the calculated average is less than 3, which is not desirable in the adult curriculum.

Question 2: How can be the desirable status of adult education curriculum in post-elementary?

Table 2. Descriptive indices of research variables (desirable status).

\begin{tabular}{|c|c|c|c|c|c|c|c|c|c|}
\hline Variables & Number & Average & Middle & extent & $\begin{array}{l}\text { Standard } \\
\text { deviation }\end{array}$ & Variance & $\begin{array}{l}\text { variation } \\
\text { range }\end{array}$ & Minimum & Max \\
\hline philosophical foundations & 25 & 3293. & 3286. & 3143. & 0624. & 0390. & 3856. & 1143. & 5000. \\
\hline sociological foundations & 25 & 3456. & 3666. & 4000. & 0619. & 0518. & 4000. & 1000. & 5000. \\
\hline psychological foundations & 25 & 3430. & 3600. & 3600. & 0698. & 0486. & 3800. & 1200. & 5000. \\
\hline political foundations & 25 & 3514. & 3614. & 4000. & 0666. & 0443. & 3286. & 1561. & 4856. \\
\hline content & 25 & 3416. & 3333. & 4000. & 0658. & 0565. & 4000. & 1000. & 5000. \\
\hline goals & 25 & 3460. & 3333. & 4000. & 0803. & 0645. & 4000. & 1000. & 5000. \\
\hline evaluation & 25 & 3484. & 4000. & 4000. & 0836. & 0600. & 4000. & 1000. & 5000. \\
\hline teaching and learning strategies & 25 & 3431. & 3666. & 4000. & 0859. & 0638. & 4000. & 1000. & 5000. \\
\hline learning time and space & 25 & 3566. & 3833. & 4000. & 0635. & 0540. & 3833. & 1166. & 5000. \\
\hline teaching and learning activities & 25 & 3569. & 3636. & 4000. & 0582. & 0338. & 3000. & 1626. & 4626. \\
\hline learning materials and resources & 25 & 3422. & 3480. & 3480. & 0521. & 0262. & 2660. & 2000. & 4660. \\
\hline
\end{tabular}

It is clear in Table 2; the correct answer to all the research questions is compiled. Also the mean of all variables is above the mean of 3. Moderate and fashion show that most respondents chose options 3 and 4 . Each research question was analyzed separately using the partial least squares technique. Finally, the overall model of the research was tested using the same technique. Based on this table, the desirable status of the research variables is presented. According to the calculations, the average of all the variables calculated has increased. This evaluation indicates that experts need to revise and upgrade the components of the desirable adult curriculum component.

Based on the results of the measurement model shown in Figure 1, the observed factor load has a magnitude greater than 0.3 in all cases, indicating that there is a good correlation between the observable variables and their hidden variables. Therefore, it can be concluded that each of the main variables has been correctly measured and the results of this scale can be tested with research hypotheses. 
Table 3. Convergent validity and reliability of research variables.

\begin{tabular}{llll}
\hline & Cronbach's alpha & AVE & CR \\
\hline philosophical foundations & 0.693 & 0.549 & 0.844 \\
sociological foundations & 0.826 & 0.631 & 0.896 \\
psychological foundations & 0.684 & 0.606 & 0.836 \\
political foundations & 0.846 & 0.598 & 0.866 \\
content & 0.806 & 0.631 & 0.849 \\
goals & 0.681 & 0.592 & 0.699 \\
evaluation & 0.852 & 0.648 & 0.854 \\
teaching and learning strategies & 0.644 & 0.563 & 0.682 \\
learning time and space & 0.843 & 0.581 & 0.899 \\
teaching and learning activities & 0.695 & 0.632 & 0.808 \\
learning materials and resources & 0.816 & 0.601 & 0.864 \\
Teamwork & 0.685 & 0.623 & 0.884 \\
\hline
\end{tabular}

Cronbach's alpha for all variables was greater than 0.6 so all variables were validated. The mean value of the variance extracted (AVE) is always greater than 0.5 , so convergent validity is also confirmed. The composite validity $(\mathrm{CR})$ value is also greater than the AVE.

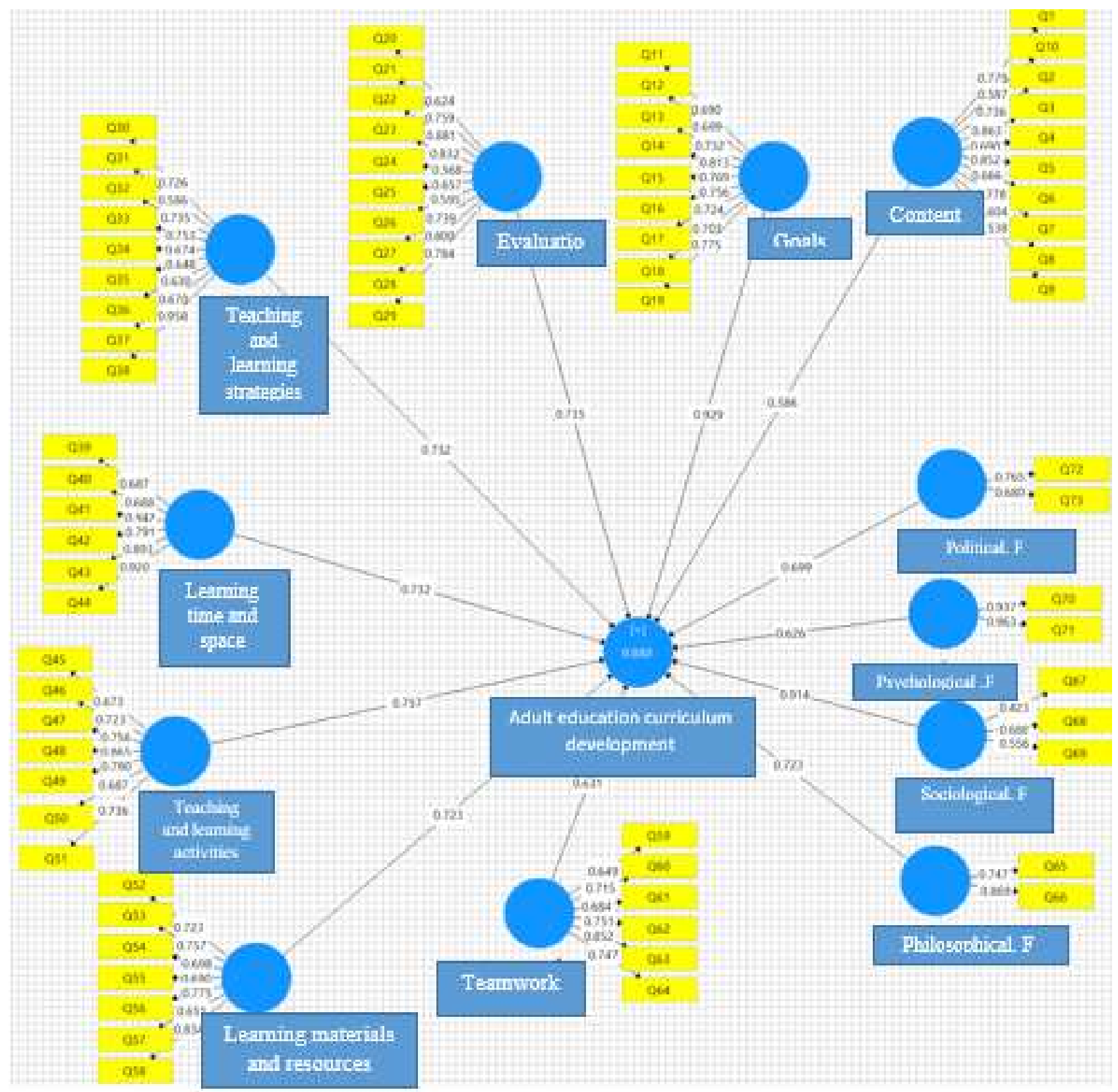

Figure 1. External partial least squares diagram (measurement model). 


\subsection{Testing Research Variables in the Quo Status}

Table 4. Status of research variables (status quo).

\begin{tabular}{llll}
\hline Variables & Factor load & T statistics & Rating \\
\hline philosophical foundations & 0.681 & 9.98 & 7 \\
sociological foundations & 0.47 & 9.876 & 12 \\
psychological foundations & 0.63 & 7.232 & 9 \\
political foundations & 0.587 & 7.267 & 10 \\
content & 0.538 & 3.385 & 11 \\
goals & 0.657 & 2.509 & 8 \\
evaluation & 0.832 & 2.375 & 2 \\
teaching and learning strategies & 0.784 & 5866. & 4 \\
learning time and space & 0.791 & 3621. & 3 \\
teaching and learning activities & 0.759 & 495. & 5 \\
learning materials and resources & 0.893 & 6.104 & 1 \\
Teamwork & 0.724 & 8.534 & 6 \\
\hline
\end{tabular}

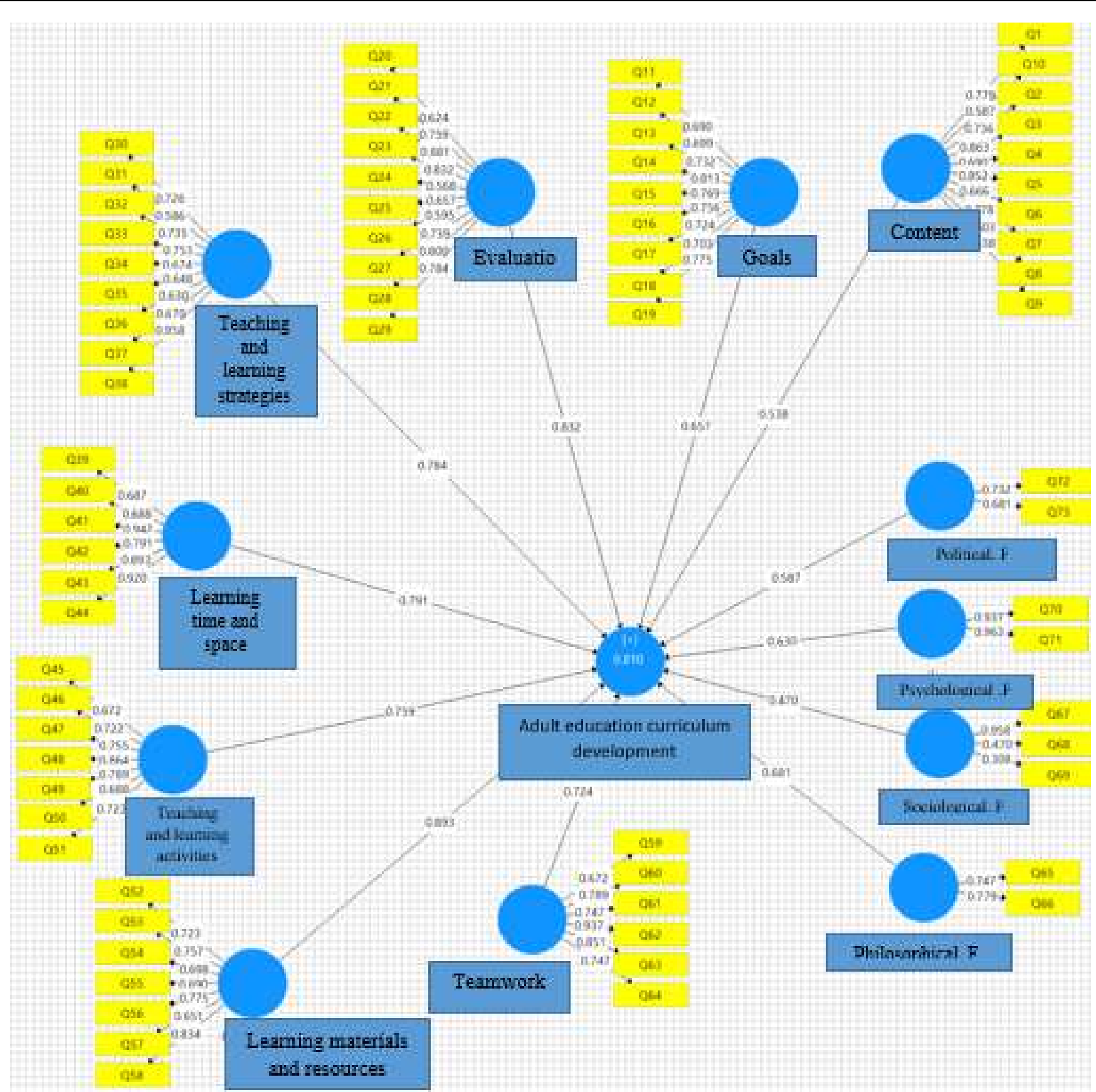

Figure 2. Graphic partial least squares graph of general research model (status quo). 


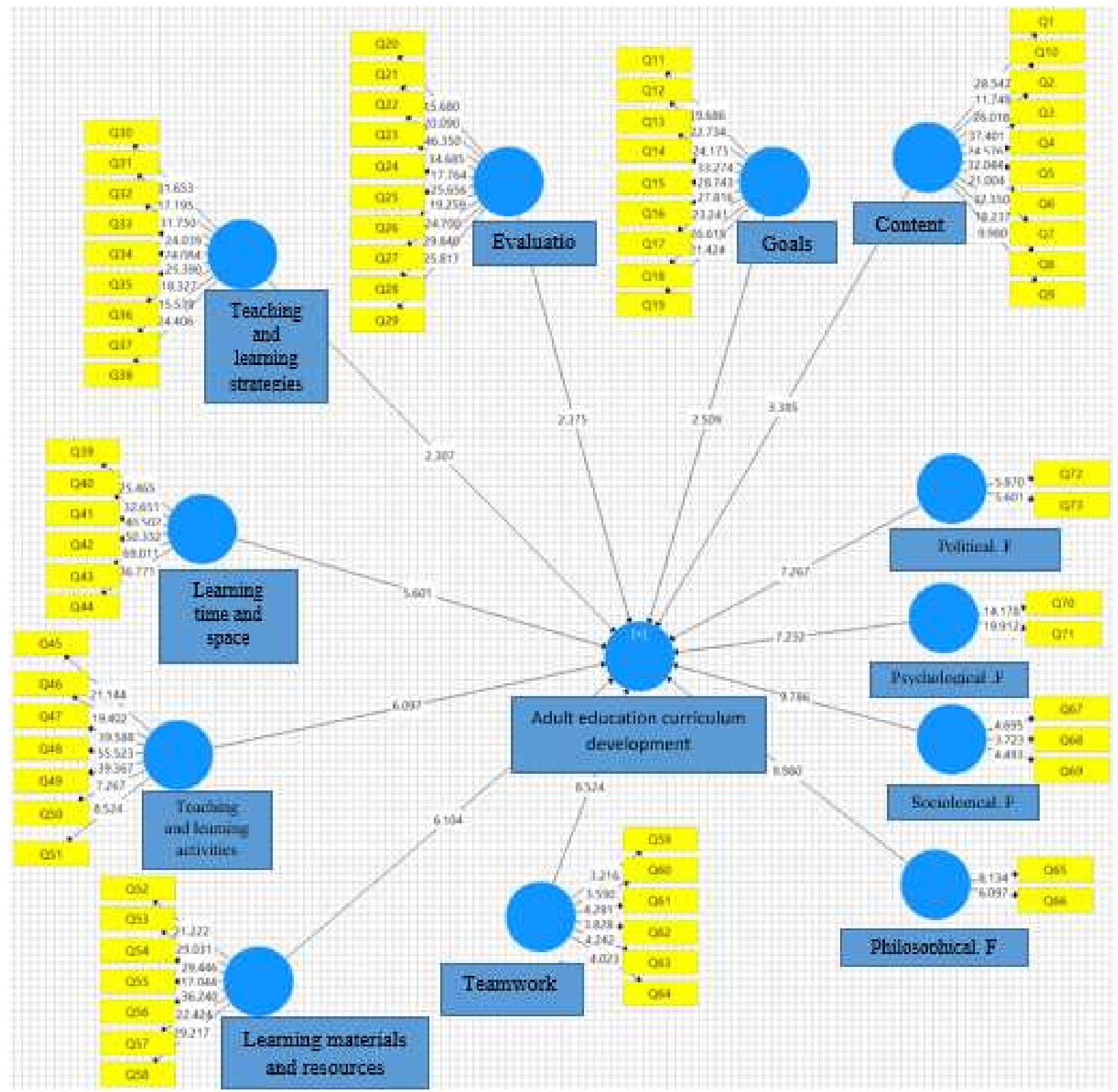

Figure 3. T-value statistic diagram of general research model with Bootstrapping technique (status quo).

\subsection{Testing Research Variables in Desirable Condition}

The relationship of the variables studied in the research is tested based on a causal structure with PLS partial least squares technique. In the general research model depicted in Figure 4, the measurement model (relationship of each of the variables visible to the hidden variable) and the path model (relationship of the hidden variables to each other) are calculated. To evaluate the significance of the relationships, the t-statistic was calculated using the bootstrapping technique presented in 5. In this model, which is the output of the Smart PLS software, we summarize the results of the standard factor loadings of the research variables relationships. Testing the research hypotheses based on the relationships of each variable is also presented separately. 


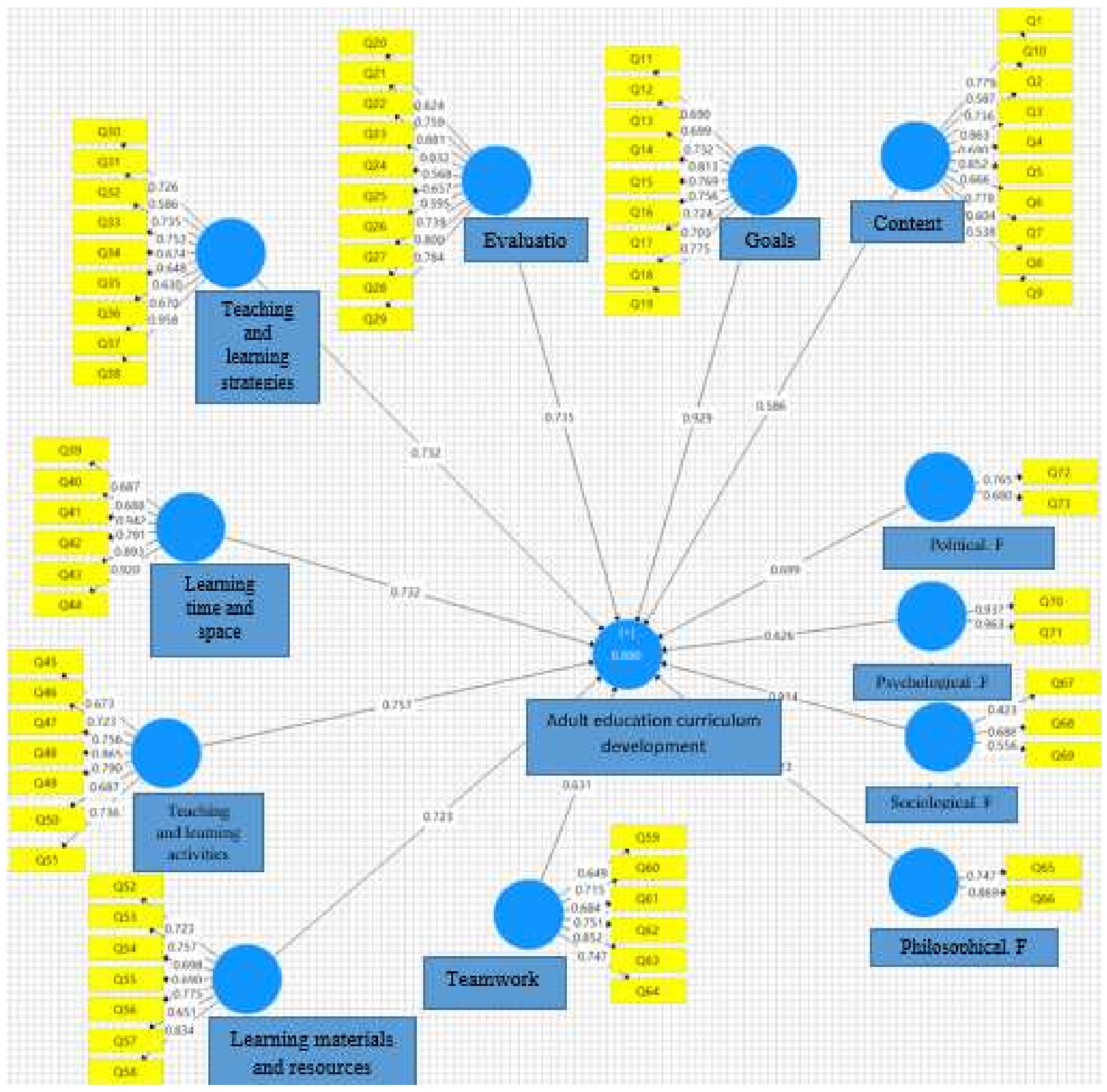

Figure 4. Partial least squares technique diagram of general research model (desirable status).

Table 5. Independent t-test for estimating the difference between the current and desirable situation.

\begin{tabular}{llllllll}
\hline \multirow{2}{*}{ Research variable } & \multirow{2}{*}{ Condition } & \multirow{2}{*}{ Average } & \multirow{2}{*}{ Average difference } & \multicolumn{2}{c}{ Assume variance equality } & \multicolumn{2}{c}{ Significance of mean difference } \\
\cline { 5 - 8 } & & & & Significance & T & Significance \\
\hline Adult Curriculum Design in & quo status & 3011. & \multirow{2}{*}{0929.} & 6319. & \multirow{2}{*}{0002.} & $3.416-$ & 0003. \\
Post-elementary & Desirable status & 394. & & & & $3.228-$ & 0004. \\
\hline
\end{tabular}




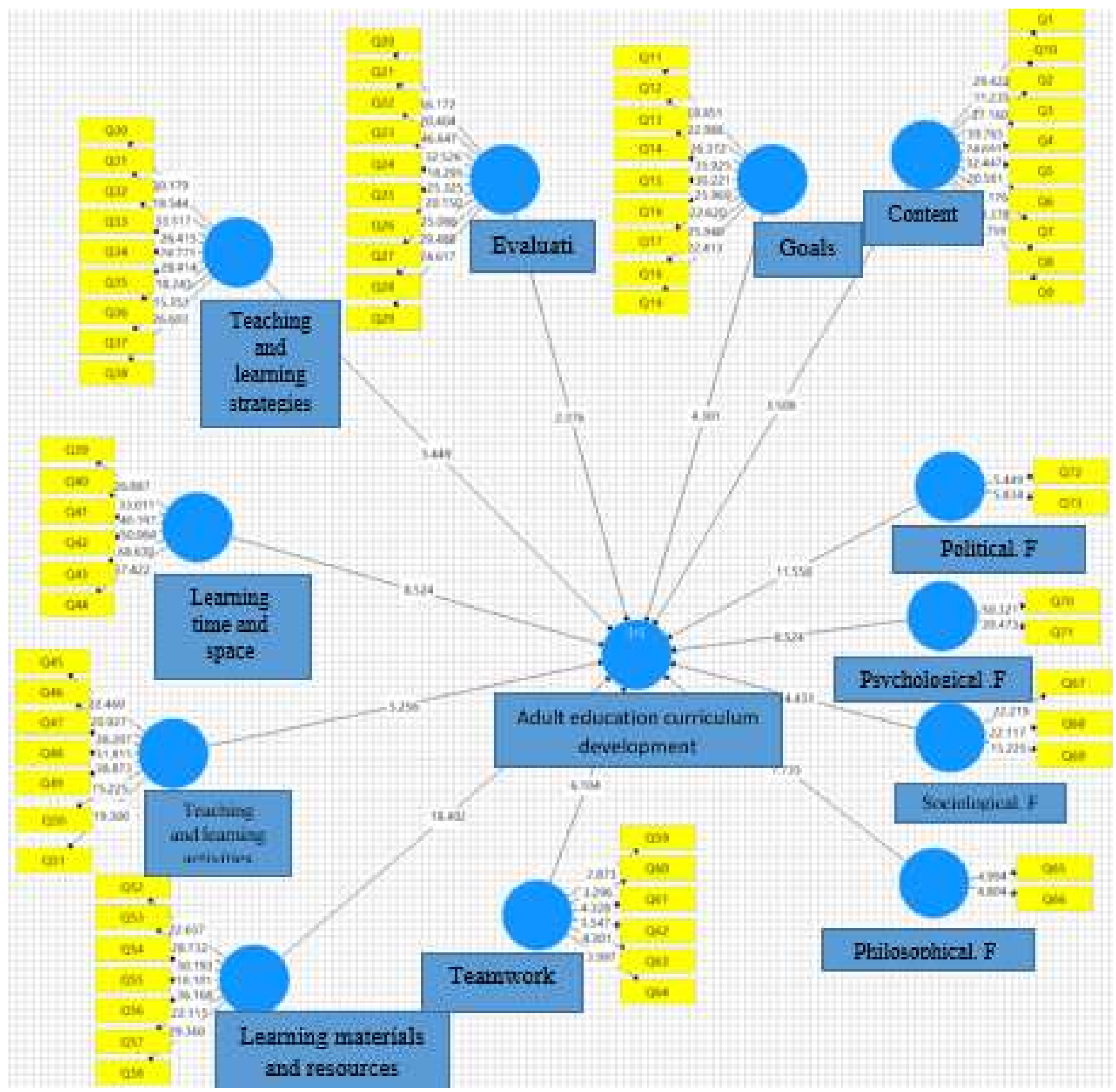

Figure 5. T-value statistic diagram of general research model with bootstrapping technique (desirable status).

In the post-elementary adult education curriculum design variable, the value is significantly smaller than the error level, $f=6.319$ and 0.002 significant because the variance of the quo status and the quo status are heterogeneous, we use the second line because t equals $228 / 3$ and significance is $4 . . /$, so the difference of experts' viewpoints in designing adult education curriculum in post-elementary school is better than the quo status. This difference indicates there is a difference in the status of the program implementation compared to the quo status.

\section{Discussion}

From the experts' point of view, all the twelve components of the adult education curriculum, including philosophical, psychological, content, objectives and........... has not acceptable situation. The findings of Ebrahimzadeh and Mohammad Davoodi's research (2009) also showed that the main components of adult education in the country include technology, course management, coaching skills, educational space design, learning approaches and educational planning, goals, evaluation system, educational content, the principles, methods, roles, and competencies are not at the desired level. Dehghani [20] also showed that the cognitive and attitudinal goals of the five-year literacy movement have been achieved at a relatively desirable level. And the content of the curriculum in different dimensions was not desirable. In explaining this finding, it can be stated that the goals of adult 
education curriculum in post-elementary education are probably not based on the educational needs of adults with entrepreneurial, process-oriented and research-oriented approaches. As mentioned, the conceptual scope of adult education goals is varied and varied due to the immense needs of adults in the psychological, economic, religious, political, cultural, and other fields.... Therefore, one of the major causes of undesirability of the goals of the adult curriculum in the post-elementary is the neglect of the social, cultural, economic, and......... design goals. Kurd Noghani (1998) showed that the most important causes of failure to achieve literacy goals are neglect of social, economic and cultural needs of learners. For example, in designing goals, content, educational strategies, and other elements of the curriculum, less attention is given to housework, women's fertility, women's family business, and child rearing. The research also showed that the quality of adult education programs in educational resources, teaching methods, teaching aids, etc. is low. This has led to the inefficiency of the adult curriculum [21].

The results of the descriptive statistics showed that from the point of view of experts, twelve components of qualitative findings were identified as the main components of the post-elementary education curriculum. On the other hand, the demetel method showed that the affective criteria in the curriculum include goals, teaching strategies and content, and the influential components consisting of teaching activities - learning, learning time and space, cardio, evaluation, learning materials and resources. This finding is in line with the results of Ebrahimzadeh and Mohammad Davoodi (2009). Ebrahimzadeh and Mohammad Davoodi (2009) also showed that the main components of adult education showed that technology components, course management, coaching skills, educational space design, learning approaches and educational planning on goals, evaluation system, educational content, principles and methods, roles, and competencies are effective. In explaining this research finding, it can be stated that the nature of goals is influential on the type of content, learning environment and learning strategies, and so on 'because of knowledge and procedural goals require linear and mechanical content. An instructional strategy tailored to these goals is also an explanatory and lecture-based teaching method. In contrast, goals related to the development of learners' creativity and critical thinking are achieved through indirect teaching strategies such as induction, problem solving, and so on. Therefore, the content structure and consequently educational strategies, learning resources and evaluation were form based on the nature of the educational goals. In the present study, one of the experts also found direct training strategies appropriate to convey structured content with predetermined and linear goals. Indirect training is useful for fostering creative and critical thinking. Of course, in his view, the usefulness of both approaches depends on mastery, tip-making, the appeal of the word, and the ability to motivate and guide coaches. According to one expert, designing time and space for education also depends on the nature of the goals and the quality of the educational content. This means that sometimes it is not possible for adults to teach one subject at a time and there is no proper training environment for such activities. Thus interacting with real and virtual social and political environments can replace the classroom teaching environment. Or, when the adult curriculum is aimed at social education, active citizenship, social responsibility, or enhancing learners' critical thinking, educational strategies are also shaped by interactive and participatory learning

Knowles introduces the adult self-directed learning model as instructional strategies influenced by learners' content and individual differences. Based on this model, situational teaching means that different instructional strategies are used with regard to the goals, content, readiness, ability and motivation of learners. In this regard, trainers play various roles from transmitter and facilitator to inclusive self-direction with regard to the content and characteristics of learners [22]. Based on the qualitative findings of this study, the choice of training space and time are influenced by factors such as educational goals, content and strategies. This impact can be explained by the proportionality feature. For example, the appropriateness of the number of learners with teaching methods, learning environments, teaching aids, and evaluation methods should be considered. Participatory approaches such as group discussion, seminars, conferences, journal clubs, brainstorming, etc. require a limited number of participants [23]. Or it is important to teach skills and hands-on activities to balance the learning environment with the number of learners. Teamworking as a component of the curriculum, should also be influenced by content goals, content, and instructional strategies such as activitycentered, heterogeneous be proportionate, ethical and inclusive [24].

Knowles's (1998) theory study is another reason for the interplay of elements of adult education curriculum including philosophical, psychological, political, sociological, goals, content, educational strategies, learning resources. Because Knowles's theory also considers the most important factor in determining the goals of adult education with regard to adult characteristics. The features of this theory include: adult selfsufficiency and self-healing, adult experience in various social roles, adult intentions and desires for learning, and learning to meet immediate needs. Adults have independent self-concept and self-direction. So they have valuable experiences, they can share in learning. Thus, there is an intrinsic relationship between psychological foundations, educational goals and strategies, and learning resources. Learning strategies derived from educational foundations can consist of helping learners to express their expectations, identify their needs, identify problems, and facilitate material conditions conducive to interactive and participatory learning and learning. Abdullah [25] also introduces the most important factor in the adult education curriculum in the selfdirected learning model to fit goals, content with educational 
needs. He puts forward the underlying hypothesis of a selfguided learning model; if the curriculum is tailored to learners' abilities, needs, and motivations, it leads the learner to self-directed and effective learning. In fact, the first thing to consider in relation to the goals of adult education in the learning process is that the goals of adult education should be designed based on the philosophical, sociological, psychological, political, entrepreneurial, process oriented, and research-oriented principles, learners' needs, their basic and actual issues in the environment [26].

\section{Conclusion}

Miziro [27] considers the application of participatory teaching methods to enhance critical thinking effective in adult learning [28]. The results showed that twelve components constitute the main foundation of adult curriculum in the postelementary. These components included philosophical foundations, sociological foundations, psychological foundations, political foundations, content, goals, evaluation, teaching and learning strategies, learning time and space, teaching and learning activities, learning materials and resources, and teamworking. Also the results of this study showed that there is a significant difference between the current situation and the desirable status of adult education curricula in elementary and post-elementary education. The results of this study suggest:

i. develope and designe the goals, content, teaching and learning strategies, evaluation, learning time and space, teaching - learning activities based on philosophical, sociological, political and psychological principles.

ii. Adapt goals of adult education based on learners' real needs with an entrepreneurial, inclusive, and researchoriented approach.

iii. Designe objectives in three areas of knowledge, insight and skill.

iv. Designe the goals according to indigenous values, human values and social norms.

v. Organize and designe the content with connectivity, comprehensiveness, fit, interactive, contextual and flexibility features.

vi. Focus on fostering creative, critical thinking and fostering a research spirit in content design

vii. Objectives provide and create social, political, responsibility, role-playing, strengthening verbal and non-verbal communication skills, self-direction and decision making.

viii.Evaluate with a process-based approach in cognitive, emotional, insight, and skill dimensions.

ix. Integrate direct and indirect teaching strategies according to the nature of the goals, content, and teaching position.

$\mathrm{x}$. Use the interactive spaces with two simultaneous and asynchronous in-person and virtual approaches, given the nature of the goals and content

xi. Use diverse, flexible and resilient learning environments.

\section{References}

[1] Ryan, J. (2005). Improving teaching and learning practices for international students: implications for curriculum, pedagogy and assessment. New York: Routledge. Abedii, Dehaghi, Lotfali (2002). Review of Literacy Programs Fit to the Needs and Conditions of Literacy Students, Isfahan, Faculty of Education.

[2] Ebrahimzadeh, Isa and Mahmoud Davoodi, Amir Hossein (2009). Investigating the Principal Components of Adult Education to Present an Appropriate Model in Iran, Journal of Educational Leadership and Management, Islamic Azad University of Garmsar Branch, Third Year, No. 4, and pp. 2933.

[3] Aqazadeh, Moharram et al. (2016). In a study titled: Evaluation of Adaptation of Literacy Courses to Higher Education Adoption Goals from the Teachers' Viewpoint, Tehran: Literacy Movement Organization.

[4] Robinson, Pant (2003). Existing research on adult literacy. Roeper Review, 25 (3), 280-329.

[5] Aberge, R., Mogstad, M., \& Peragine, V. (2011). Measuring long-term inequality of opportunity. Journal of Public Economics, 95 (3), 193-204.

[6] Jarvius, Peter (2012). Adult Education and Continuing Education. Translated by Gholamali Sarmad. Tehran. Side Publications and Fourth Edition.

[7] Mir Hosseini, Zohreh and Arjomandnia, Ali Akbar (2008). Content Analysis of Non-Textbook Students' Literacy Movement in Tehran, Quarterly Journal of Islamic Azad University, No. 1.

[8] Abedii, Dehaghi, Lotfali (2002). Review of Literacy Programs Fit to the Needs and Conditions of Literacy Students, Isfahan, Faculty of Education.

[9] Haghi, Nasser (1992). Causes of Illiteracy in Basic Literacy Students, Tehran: Literacy Movement Organization.

[10] Lotfi, Ahmad (1996). Investigating the Level of Basic Literacy Students' Reading Skills, Tehran: The Literacy Movement - Lindsay \& Johnson, 1992, for a more extended.... from whom one initially learned it-Allen \& Jacoby 1990.

[11] Mahnaei, Seyyed Qasim (2000). Investigating the Reasons for Fifth Adult Literacy Attendance of Yazd 1999, Kohkiloyeh \& Boyer Ahmad Provincial Planning and Literacy Office, School of Human Resources Training, 68.

[12] Ojaghi, Ali; Hashemnejad, Alireza (1999). The Effect of Applied Education on Preventing Academic Dropout of East Azarbaijan Students, Office of Planning and Human Resources Training of East Azarbaijan Province.

[13] Shah Aliloo, Behzad; Ghannimi, Mohammad (1998). Investigating Barriers to Illiterate Absorption Foundation of West Azerbaijan Literacy Movement in 1996, Urmia: Literacy Movement of West Azerbaijan Province.

[14] Hushangi et al. (1990). A Study of the Causes of Academic Deprivation of Students, Tehran: Literacy Movement Organization.

[15] Ghaffari, Saeed (2000). Adult and Toddler Education. Tehran: Print. 
[16] Shafiei, Nahid. (2012). Adult Education Website. Islamic Azad University, Islamshahr Branch, Second Edition.

[17] Fundamental Transformation Document. (2014). Ministry of Education, Higher Education and Cultural Revolution Council, Tehran.

[18] Perrin, For MemRS (2009). Sound of evaluation, Sage, Thousand Davidson, EJ 2005, Evaluation methodology basics: the nuts and bolts of sound evaluation, Sage, Thousand Oaks, California.

[19] Secretariat of Higher Education Council. (2009). Approvals Collection. Tehran: School.

[20] Dehghani, Marzieh; Amin Khandaghi, Maghsoud; Jafari Sani, Hossein; Nogani Dukht Bahmani, Mohsen. (2011). Exploring Conceptual Patterns in the Curriculum Area: A Critique of Studies Conducted by the Pattern Design Approach in the Curriculum, Curriculum. Research Principles of Education, 136-1999.

[21] Kurd Noghani, Razor (1998). Predictors of Illiteracy Returns to Literacy Graduates. Journal of Sociology of Education, Successive 1 (1), pp. 60-61.

[22] Yarmohammadian, Mohammad Hossein. (2010) Principles of Curriculum Planning, Book Memoirs Publishing, Fourth Edition.
[23] Kurd Zangana, Shahnaz (2005). Evaluation of the Relevance of Behavioral Goals in Persian Basic Course Book with Learning Levels, Tehran: Literacy Movement Organization.

[24] Mohammadi, Mehdi and Marzoukhi, Rahmatollah (2016). Higher education curriculum based on a lifelong learning approach - a qualitative approach. Journal of Higher Education Curriculum Studies, Spring \& Summer 2016, Volume 6, Number 13.

[25] Abdullah, M. H. (2008). Adult Participation in Self-Directed Learning Programs. International education studies. www.ccsenet.org, journal. Vol 1, no, 3, p 68.

[26] Mulayi, Behzad (1999). Investigating the Factors Affecting Adult Sisters' Failure to Attend Literacy Movement From the Perspectives of Sanandaj Teachers, Planning and Human Resources Training Office, Kurdistan Province.

[27] Miziro, O. K. (2009). Automotive engineering curriculum development: case study for Clemson University, Journal of Great Lakes Research, Vol. 28, No. 1, p. 11.

[28] Mokhabat, Mohammad; Ghodrati, Mehdi and Rezapurlakani, dawn. (2014). Content Analysis of Learning Indicators in Educational Books of the Literacy Movement Follow-Up Study Groups. Journal of Modern Educational Thoughts. Volume 9, Number 2. Pages: 109-130. 